\title{
Friction Effects between Ultrasonic Cutting Blade and Sheet Stack
}

\section{Conference Paper}

Author(s):

Deibel, Karl-Robert; Wegener, Konrad; Boos, Jens

Publication date:

2012

Permanent link:

https://doi.org/10.3929/ethz-a-007598816

Rights / license:

In Copyright - Non-Commercial Use Permitted

Originally published in:

https://doi.org/10.1109/ULTSYM.2012.0667 


\section{Friction Effects between Ultrasonic Cutting Blade and Sheet Stack}

\author{
Karl-Robert Deibel, Konrad Wegener \\ Department of Mechanical and Process Engineering \\ Institute of Machine Tools and Manufacturing \\ ETH Zurich \\ 8092 Zurich, Switzerland \\ Email: deibel@iwf.mavt.ethz.ch \\ Telephone: +41446322414
}

\author{
Jens Boos \\ inspire $A G$ \\ ETH Zurich \\ 8092 Zurich, Switzerland
}

\begin{abstract}
Ultrasonic vibration assisted machining is known to reduce friction forces for various processes and materials. In this paper, the friction forces between an asymmetrical cutting blade and sheet stack for different cutting velocities are investigated. Materials used for the sheets are plain label paper and polyethylene terephthalate. The cutting blade operates at a resonant longitudinal mode, resulting in a discontinuous relative movement between blade surface and stack. Along the normal vector of the cutting edge, the friction force reduction changes with the amplitude of the longitudinal mode of the blade. It is shown that for low cutting velocities no friction force is visible, and at higher cutting velocities friction increases.
\end{abstract}

\section{INTRODUCTION}

In recent years, a substantial amount of research has been done on ultrasonic vibration assisted machining. The hybrid process allows conventional manufacturing processes to be enhanced with high frequency vibrations, to reduce forces [1], increase workability of hard materials [2], improve surface quality, and increase tool life [3]. For the print and paper industry, the need for new technologies to lower production costs is of major interest. The cutting of paper sheet stacks is an essential process in the production line that calls for high speed and high precision. Presently, conventional guillotining of sheet stacks is used to bring paper coming from offset printing or gravure printing into the correct dimensions with a single translational guillotine or swivel guillotine. One key advantage of ultrasonic vibration assisted cutting as a hybrid process is allowing conventional cutting to be enhanced by creating an oscillating movement of the tool edge while cutting. It has been shown that ultrasonic vibration assisted cutting of food materials can reduce cutting forces [4] due to reduction in friction forces.

There are three basic vibration modes that can be used individually or in combination for ultrasonic vibration assisted cutting: longitudinal, transversal, and lateral. At the cutting edge, a longitudinal mode has a maximum displacement in cutting direction, a transversal mode has a maximum displacement perpendicular to the cutting direction and cutting edge, and a lateral mode has a maximum displacement perpendicular to the cutting direction and parallel to the cutting edge.
Rozner et al. [5] showed that ultrasonic vibration effects the friction forces between metals in strip drawing. For the metal drawing process a reduction in drawing and die forces was observed. Static friction forces subject to vibrations are reduced and a change in elastoplastic deformation of the contact in a static friction joint is observed [5]. Another investigation in plastic forming showed that ultrasonic oscillations apply additional acoustic stress that affects friction resulting in lower drawing forces [6]. Dynamic friction forces are also reduced when under the influence of vibrations [7]. Littmann et al. [8] conducted thorough investigations on friction force reduction when applying longitudinal vibrations and developed an analytical model that matches the qualitative observations. Friction occurring during the ultrasonic vibration assisted process was used to study surface characteristics on microscopic devices [9]. While most applications use vibrations parallel to the process's primary direction of motion, longitudinal and transversal vibrations affect sliding friction. An increasing amplitude showed an increased reduction in friction forces for aluminum, brass, copper, and stainless steel [10]. Friction reduction in longitudinal vibration direction was larger than in transversal vibration direction. The above mentioned models mostly rely on the Coulomb friction model, where the discontinuous duty cycle [3] lowers the average measured friction force.

In this investigation, the friction forces between sheet stacks and asymmetrical steel tool are discussed for a range of cutting velocities at constant vibration frequency and amplitude.

\section{EXPERIMENTAL PROCEDURE AND MATERIALS}

In order to experimentally test the frictional behavior between sheet stacks and flat metal surface of the cutting blade, the experimental setup shown in Figure 1 is used. As visible in Figure 1, the sheets are clamped with a force of $2000 \mathrm{~N}$ and are aligned at the front to allow all sheets to contact the metal surface of the cutting blade. The normal force is therefore parallel to the sheets, and the friction force is parallel to the normal vector of the sheets and perpendicular to the cutting edge. Total height of the stack is $7 \mathrm{~mm}$. The paper material used is plain label paper on which typical designs 


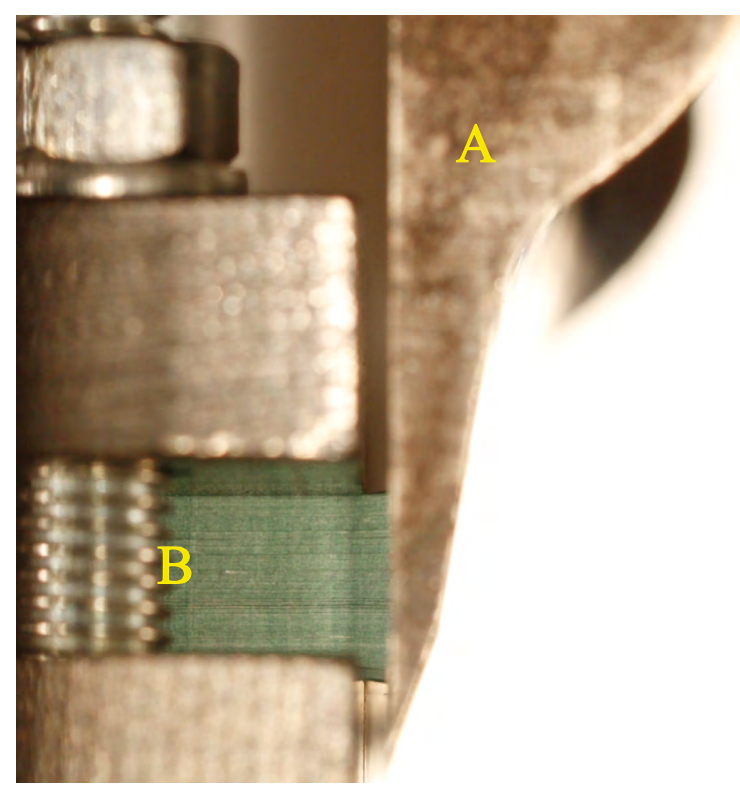

Fig. 1. Experimental setup with cutting blade (A), and clamped stack (B). The stack juts out $2 \mathrm{~mm}$.

are printed via offset printing with an average thickness of $0.06 \mathrm{~mm}$ and an area density of $68 \mathrm{~g} \mathrm{~m}^{-2}$. As the second test material, polyethylene terephthalate (PET) sheets with an average thickness of $0.08 \mathrm{~mm}$ are used.

The cutting blade used for the experiments is a specially designed asymmetrical cutting blade, which was optimized for resonance operation at $35 \mathrm{kHz}$ with a longitudinal mode across the entire blade as shown in Figure 2. The minor bending mode at the cutting edge is neglected in the experiments, because the measurement data is obtained $5 \mathrm{~mm}$ above it. The cutting blade was milled out of X37CrMoV5-1 with the contact surface finished by grinding. For exciting the cutting blade, an ultrasonic piezoelectric transducer is connected to the M8 screw at the top. The vibration amplitude at the middle of the cutting edge is set at $1.33 \mathrm{~m} \mathrm{~s}^{-1}$ for all experiments. At this amplitude, the PET sheets do not melt during the low cutting velocity experiments as was observed with higher amplitudes, and no significant thermal effects were observed. To avoid the effect of increased dry friction due to fiber rearrangement as discussed in [11] and [12], the experiments regarding the friction of the paper stack and cutting blade are preceded with five runs. All experiments use the same sliding direction and no contact occurs during reset.

All measurements are recorded with a three axis Kistler force measurement platform with a sensor crosstalk of approximately $1 \%$. Measurement data consisting of friction force, normal force, and position was recorded synchronously with LabView at a sampling rate of $10000 \mathrm{~Hz}$.

\section{RESUlTS AND DISCUSSION}

Testing the frictional behavior between the cutting blade and paper sheet stack and PET sheet stack is done using the cutting velocities between $10 \mathrm{~mm} \mathrm{~min}^{-1}$ to $20000 \mathrm{~mm} \mathrm{~min}^{-1}$. The

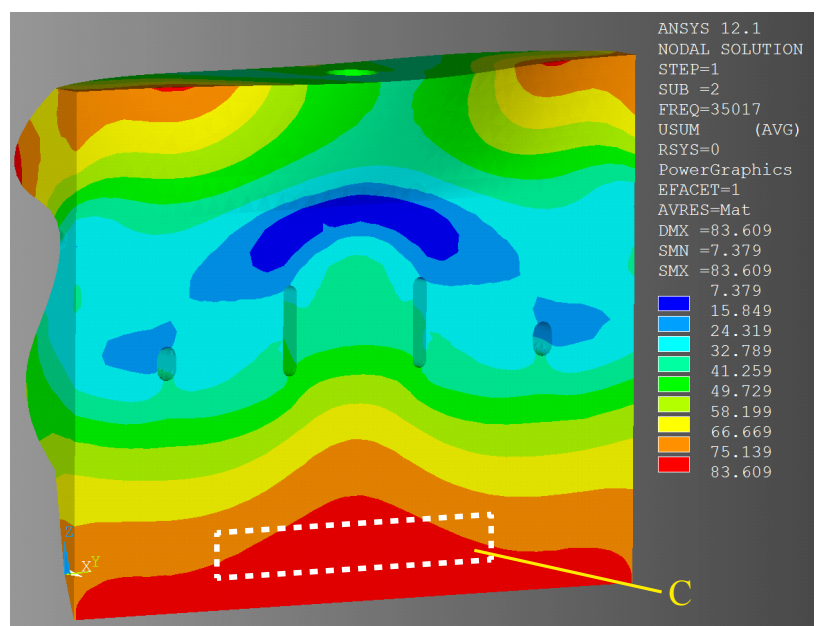

Fig. 2. FEM modal analysis of the asymmetrical cutting blade used for the experiments. Shown is the longitudinal mode at $35 \mathrm{kHz}$. The white dashed area $(\mathrm{C})$ indicates the measuring position for the friction force between blade and stack. Colors show absolute values of displacement with an increasing amplitude at the cutting edge.

impact of the ultrasonic vibration on the friction force depends on the frequency and amplitude of the vibration and the resulting discontinuous relative movement. The displacement during vibration assistance is calculated by

$$
x(t)=v_{f} t+x_{0} \cos (\omega t)
$$

with $x$ being the displacement, $v_{f}$ the cutting velocity, $\omega$ the vibration frequency, and $x_{0}$ the vibration amplitude. The velocity during vibration assistance is calculated by

$$
v_{\text {rel }}(t)=v_{f}-\omega x_{0} \sin (\omega t)
$$

with $v_{r e l}$ being the relative velocity. To understand the ultrasonic vibration assisted friction forces, the modified Coulomb friction model presented in [8] is considered. Ultrasonic friction force is calculated by

$$
F_{R}=F_{C}\left(\frac{2}{\pi} \sin ^{-1}\left(\frac{v_{f}}{\omega x_{0}}\right)\right)
$$

for $v_{f}<\omega x_{0}$, with $F_{R}$ being the average friction force, and $F_{C}$ the Coulomb friction force. It was observed that the friction force reduction is related to the amplitude of the vibration along the surface of the cutting blade (Figure 2) as shown in Figure 3. Therefore, the friction forces at the same relative position between cutting blade and stack is considered. The normal force applied is $9 \mathrm{~N}$ in all experiments.

Figure 4 shows the friction forces with and without ultrasonic vibration of the cutting blade for paper sheet stack. At low cutting velocities, the friction force reduction due to the vibrations is very high, resulting in unmeasurable friction forces. At higher cutting velocities, an increase in the friction force can be observed for conventional and ultrasonic vibrationassisted testing. Similar observations are made in Figure 5 for friction forces of PET without and with ultrasonic vibration of the cutting blade. The difference in vibration assisted friction force increase at lower relative velocity for paper than for PET 


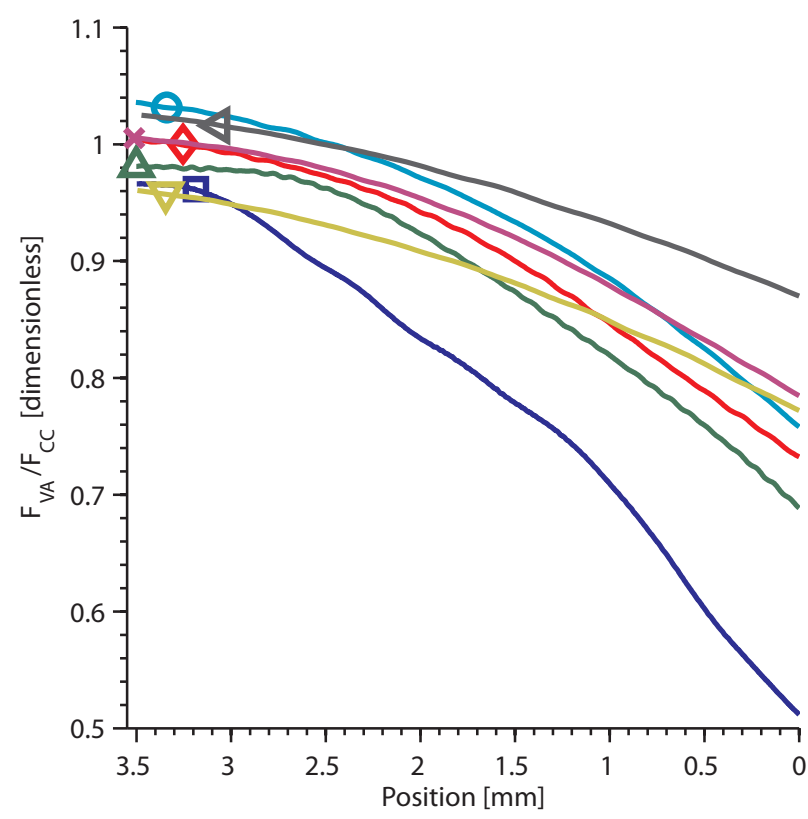

Fig. 3. Friction force reduction based on position of the stack along the blade. Here, no friction force reduction is observed $3.5 \mathrm{~mm}$ and higher above the measuring position (Figure 2) with 0 being the measurement position for the experiments. $F_{V A} / F_{C C}$ is the ratio between vibration assisted friction force and conventional friction force. Reduction is shown for $1000 \mathrm{~mm} \mathrm{~min}^{-1}$ $(\square), 3000 \mathrm{~mm} \mathrm{~min}^{-1}(\triangle), 5000 \mathrm{~mm} \mathrm{~min}^{-1}(\diamond), 7000 \mathrm{~mm} \mathrm{~min}^{-1}(\bigcirc)$, $10000 \mathrm{~mm} \mathrm{~min}^{-1}(\nabla), 15000 \mathrm{~mm} \mathrm{~min}^{-1}(\times)$, and $20000 \mathrm{~mm} \mathrm{~min}^{-1}(\triangleleft)$.

can be explained by the smaller relative displacement at high relative velocity and the bending of the paper fibers. At high relative velocity, the paper fibers flip back and forth for one vibration cycle and the actual sliding is minimal, but increases with lower relative velocity. Regarding the experiments with PET, friction forces at a low velocity range stay constant while at high velocity, an increase is observed due to the viscoelastic behavior of polymers as it is discussed in [13], which is also observed here. For polytetrafluoroethylene (PTFE) and polyamide (PA), an increase in friction at higher velocities was also observed in [14]. The increase in friction with higher relative velocity is expected regarding the modified Coulomb friction model. Regarding the friction forces of paper and PET stacks, the model cannot be applied here for high cutting velocities or lower relative velocity, because the nonlinear velocity dependency of both materials as seen in the experimental data of conventional friction force. However, the friction forces observed at low cutting velocities ( $=$ low relative velocity) are near zero for both materials and fit the modified Coulomb model well. Regarding the friction between blade and paper stack, no friction was observed for cutting velocities below $7000 \mathrm{~mm} \mathrm{~min}^{-1}$. For PET, the friction increased above $100 \mathrm{~mm} \mathrm{~min}^{-1}$.

To analyze the dependency of the friction force on the jutting of the stack, measurements with $0.5 \mathrm{~mm}$, $1.75 \mathrm{~mm}, 3.5 \mathrm{~mm}, 5.25 \mathrm{~mm}$ and $7 \mathrm{~mm}$ jut at cutting velocities $1000 \mathrm{~mm} \mathrm{~min}^{-1}, 3000 \mathrm{~mm} \mathrm{~min}^{-1}$ and $5000 \mathrm{~mm} \mathrm{~min}^{-1}$ are conducted. Figure 6 shows that the jutting has no effect on the

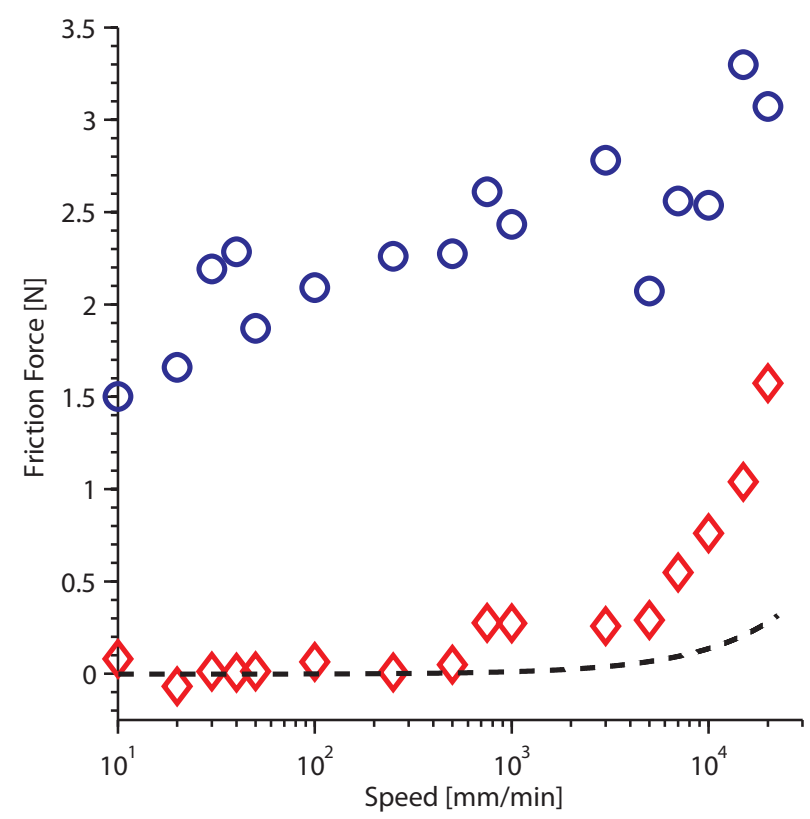

Fig. 4. Conventional $(\bigcirc)$ and vibration assisted $(\diamond)$ friction force between blade and paper sheet stack for cutting velocities between $10 \mathrm{~mm} \mathrm{~min}^{-1}$ to $20000 \mathrm{~mm} \mathrm{~min}^{-1}$. The black dashed line shows the calculated vibration assisted friction force from the modified Coulomb model with $F_{C}=1.5 \mathrm{~N}$ [8]. Measurement uncertainty is $\pm 0.3 \mathrm{~N}$.

friction forces without vibration, but vibration assisted friction forces are higher at small juts. At larger jutting, the reduced stack bending stiffness [15] has an impact on the friction force, because the the individual sheets can move along with the oscillation of the cutting blade and thereby no sliding occurs.

\section{CONCLUSION}

In conclusion, it has been shown that ultrasonic vibrations affect the friction forces between sheet stacks and metal surfaces. When using an asymmetrical cutting blade for cutting sheet material or any other material, it is important to choose a clearance angle $>0^{\circ}$ to properly utilize the effect of friction reduction of vibration assisted cutting. Regarding the friction effects between sheet material and blade, it was shown that for low cutting velocities, no friction forces were measured during ultrasonic vibration assistance, while at higher cutting velocities, reduced friction forces are observed. Vibration assisted friction forces also depend on the jutting of the clamped sheet stack.

Further investigations in finding an appropriate model for the modified velocity dependent friction need to be conducted. Thermal behavior of fibrous materials needs to be conducted as well as wear of cutting blades during vibration assisted cutting.

\section{ACKNOWLEDGMENT}

The authors would like to specially thank Sascha Weikert for the input regarding the experimental setup, and Walter Littmann for some help regarding the modified Coulomb model. 


\section{REFERENCES}

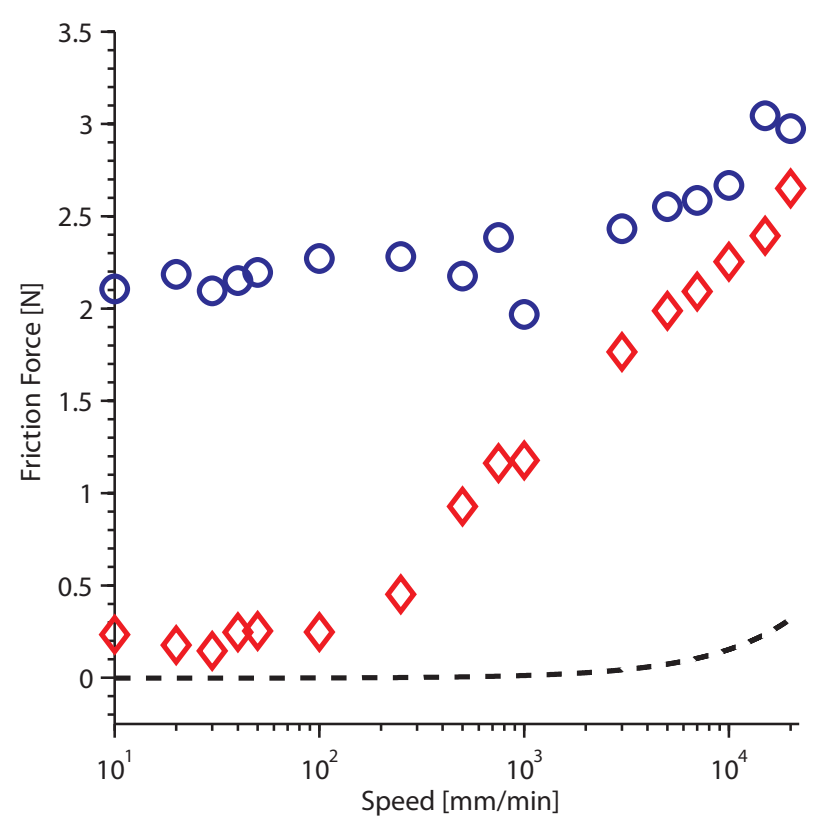

Fig. 5. Conventional $(\bigcirc)$ and vibration assisted $(\diamond)$ friction force between blade and PET sheet stack for cutting velocities between $10 \mathrm{~mm} \mathrm{~min}^{-1}$ to $20000 \mathrm{~mm} \mathrm{~min}^{-1}$. The black dashed line shows the calculated vibration assisted friction force from the modified Coulomb model with $F_{C}=2 \mathrm{~N}$ [8]. Measurement uncertainty is $\pm 0.3 \mathrm{~N}$.

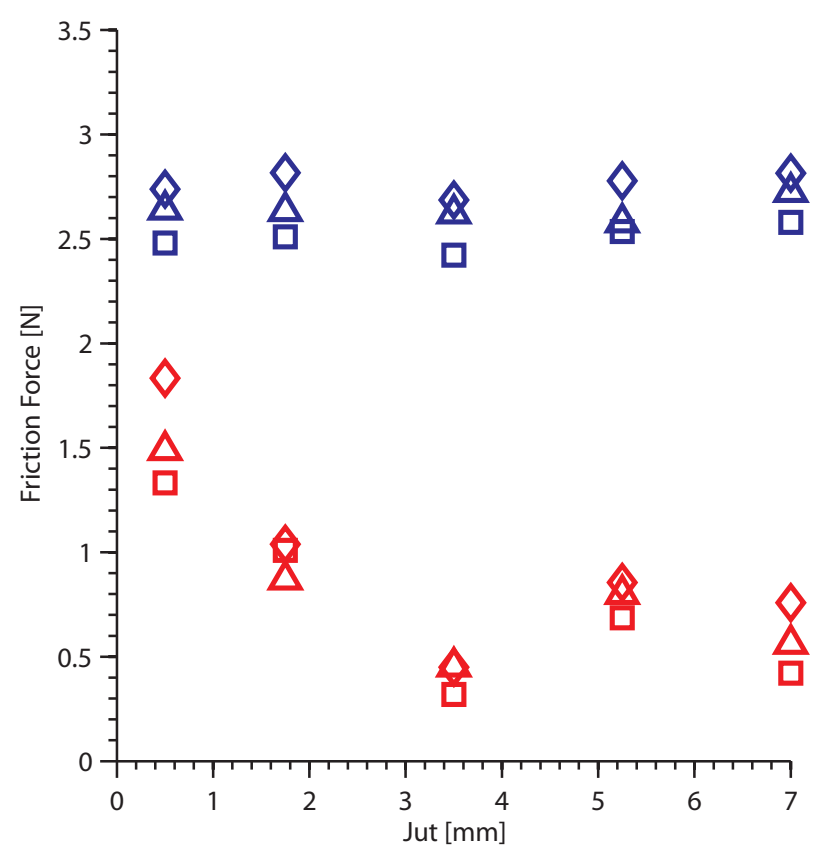

Fig. 6. Friction forces with and without vibration for different juts at $1000 \mathrm{~mm} \mathrm{~min}^{-1}(\square), 3000 \mathrm{~mm} \mathrm{~min}^{-1}(\triangle), 5000 \mathrm{~mm} \mathrm{~min}^{-1}(\diamond)$.
[1] V. Astashev and V. Babitsky, "Ultrasonic cutting as a nonlinear (vibroimpact) process," Ultrasonics, vol. 36, no. 1-5, pp. 89 - 96, 1998.

[2] E. Shamoto and T. Moriwaki, "Ultaprecision diamond cutting of hardened steel by applying elliptical vibration cutting," CIRP Annals Manufacturing Technology, vol. 48, no. 1, pp. 441 - 444, 1999

[3] D. Brehl and T. Dow, "Review of vibration-assisted machining," Precision Engineering, vol. 32, no. 3, pp. 153 - 172, 2008.

[4] Y. Schneider, S. Zahn, and H. Rohm, "Ultrasonic cutting of foods," in Ultrasound Technologies for Food and Bioprocessing, ser. Food Engineering Series, H. Feng, G. Barbosa-Canovas, J. Weiss, and G. V. Barbosa-Cánovas, Eds. Springer New York, 2011, pp. 211-237.

[5] A. G. Rozner, "Effect of ultrasonic vibration on coefficient of friction during strip drawing," The Journal of the Acoustical Society of America, vol. 49, no. 5A, pp. 1368-1371, 1971.

[6] R. Pohlman and E. Lehfeldt, "Influence of ultrasonic vibration on metallic friction," Ultrasonics, vol. 4, no. 4, pp. 178 - 185, 1966.

[7] T. Skåre and J.-E. Ståhl, "Static and dynamic friction processes under the influence of external vibrations," Wear, vol. 154, no. 1, pp. 177 192, 1992

[8] W. Littmann, H. Storck, and J. Wallaschek, "Sliding friction in the presence of ultrasonic oscillations: superposition of longitudinal oscillations," Archive of Applied Mechanics, vol. 71, pp. 549-554, 2001.

[9] P. Schwaller, P. Gröning, and A. Schneuwly, "Surface and friction characterization by thermoelectric measurements during ultrasonic friction processes," Ultrasonics, vol. 38, no. 1-8, pp. $212-214,2000$.

[10] V. Kumar and I. Hutchings, "Reduction of the sliding friction of metals by the application of longitudinal or transverse ultrasonic vibration," Tribology International, vol. 37, no. 10, pp. 833 - 840, 2004.

[11] A. Johansson, C. Fellers, D. Gunderson, and U. Haughen, "Paper friction - influence of measurement conditions," International Paper Physics Conference Proceedings, pp. 49 - 65, 1997.

[12] N. Garoff, C. Fellers, and N.-O. Nilvebrant, "Friction hysteresis of paper," Wear, vol. 256, no. 1-2, pp. 190 - 196, 2004.

[13] N. Myshkin, M. Petrokovets, and A. Kovalev, "Tribology of polymers: Adhesion, friction, wear, and mass-transfer," Tribology International, vol. 38 , no. 11-12, pp. $910-921,2006$.

[14] B.-B. Jia, T.-S. Li, X.-J. Liu, and P.-H. Cong, "Tribological behaviors of several polymer-polymer sliding combinations under dry friction and oil-lubricated conditions," Wear, vol. 262, no. 11-12, pp. 1353 - 1359, 2007.

[15] D. Gross, W. Hauger, J. Schröder, and W. Schnell, "Balkenbiegung," in Technische Mechanik 2, ser. Springer-Lehrbuch. Springer Berlin Heidelberg, 2012, pp. 87-173. 